\title{
PROPÓSITOS E PROJECTOS DA MINHA CARREIRA DE GEÓGRAFO*
}

Quando terminei os meus estudos universitários decidira-me já por uma carreira científica dentro das matérias em que hoje professo e investigo. Sem amparo nem estímulo, apesar das incertezas e limitações de vária ordem, preparei-me para ocupar um lugar no ensino superior, única [ou quasi única] actividade compatível entre nós com a investigação científica a que resolvera dedicar-me.

$\mathrm{Na}$ impossibilidade de obter uma boa preparação no campo da Geografia, procurei-a ao menos em duas ciências afins: com o Professor Ernest Fleury, do Instituto Superior Técnico, desembaracei-me na Geologia de campo; no admirável seminário que era a casa de Leite de Vasconcellos, durante seis anos de intenso convívio, familiarizei-me com os problemas e a técnica da Etnografia - e estas foram as bases de toda a minha preparação ulterior em Geografia Física e em Geografia Humana.

Em 1935 fiz uma longa e rápida viagem às colónias portuguesas do Atlântico, como professor adjunto de uma missão cultural dirigida pelo [Dr] Professor Marcello Caetano.

Em 1933 comecei a publicar e em 1936 doutorei-me, com uma tese de Geografia regional sobre "A Arrábida". Todavia as deficiências da preparação, que eu levara em Portugal tão longe quanto podia, só no ano seguinte as senti plenamente, quando comecei a trabalhar no Instituto de Geografia da Faculdade de Letras [de Paris] da Sorbonne e no Laboratório de Geografia Física da Faculdade de Ciências da mesma Universidade. Aí estagiei quatro anos, ao mesmo tempo que, durante as férias, alargava e aprofundava os trabalhos de campo em Portugal.

Em 1941 fui convidado como professor extraordinário da Universidade de Coimbra e, em 1943, nomeado professor catedrático da Universidade de Lisboa, onde [rejo] ensino as cadeiras de Geografia de Portugal e de Geografia Colonial; em 1945, colaborador dos Serviços Geológicos, a que logo dei activo concurso.

\footnotetext{
* Este texto inédito foi redigido em 1946 e retocado em 1969.
} 
Faço também parte do Centro de Estudos Demográficos do Instituto Nacional de Estatística, mas o programa de trabalho que apresentei não foi considerado oportuno pela direcção. Está correndo a minha nomeação para a Junta das Missões Geográficas e das Investigações Coloniais. [Rejo] Ministro ainda, a partir deste ano, um curso de "Estudos Olisiponenses".

Desde 1943 que dirijo teoricamente o Centro de Estudos Geográficos do Instituto para a Alta Cultura, o qual todavia só em 1945 [pode] obteve os primeiros subsídios para começar a trabalhar; em breve daremos algumas amostras do que aí se tem feito.

Publiquei até hoje mais de meio cento de títulos: estudos originais, revisões de conjunto, recensões bibliográficas, artigos de divulgação, planos de trabalho, etc.; entre eles uma monografia extensa de Geografia humana e um livro, que suponho [bem] documentado e [bem] meditado, acerca das relações geográficas da Terra Portuguesa. Colaborei com colegas e alunos em trabalhos de campo, tomei parte activa em Congressos Internacionais, ensinei e fiz conferências em Portugal e no estrangeiro. Em 1944, tive a satisfação de mostrar os resultados dos meus trabalhos de campo a um Mestre, o Professor de Martonne: ouvi-lhe gratas palavras de estímulo e de aplauso. No ano anterior fiz muitas excursões com colega alemão, o Professor Lautensach, a primeira autoridade em Geografia de Portugal: o juízo que ele formulou acerca das minhas publicações, e o convite que me dirigiu para elaborarmos juntos um estudo extenso do nosso país, aproveitando os dois volumes que consagrara ao assunto e confiando-me a renovação da maior parte dos capítulos com o resultado das minhas investigações, trouxeram-me grande alegria: pelo valor que um colega, muito mais velho e mais adiantado do que eu, atribuir ao que eu fizera ou podia fazer, e por ver um estrangeiro, que consagra ao nosso território o essencial da sua actividade, empenhar-se em obter a colaboração de um trabalhador português na refundição da sua obra ${ }^{1}$.

Viajei em Espanha, França, Bélgica, e Holanda: visitei [todas] as nossas ilhas atlânticas excepto os Açores, a Guiné e Angola. Passei à vista das Canárias, embrenhei-me numa floresta tropical, arranquei uma Welwitschia no deserto de [Kalahari] Namibe. Vi, num polder da Holanda, passarem os barcos acima da minha cabeça, desci à cratera de um vulcão extinto; visitei minas profundas e potentes instalações da indústria metalúrgica, voei sobre uma grande capital europeia, onde vivi quatro anos. Percorri montanhas pastoris e velhas aldeias convivendo com gente rural, dormindo e comendo com eles; estive no interior de uma tabanca na Guiné, onde falei com um [feiticeiro] chefe ou homem_grande, na meia obscuridade da sua casa de palha. Há mais de quinze anos que regularmente pratico o contacto com a Natureza e com os homens que vivem junto dela: se alguma coisa de vivo passou ao meu ensino e aos meus trabalhos, devo-o

1 Unicamente por motivo de outros trabalhos pessoais meus não foi possível dar execução a este projecto (1969). 
a esta fúria de correr mundo, de ver terras e gentes. Só assim se pode ser geógrafo. O gabinete, o laboratório, a tranquilidade das bibliotecas, não devem passar, para nós, de um repouso transitório no nosso fadário de andarilhos.

A colaboração com outros trabalhadores e os juízos críticos formulados acerca das minhas obras permitem-me ter hoje [bastante] confiança nos resultados científicos a que sou capaz de chegar. Obrigado, por carência de investigadores, a mover-me tanto no campo da Geografia física como na Geografia humana, vejo hoje no meu assistente, Eng. ${ }^{\circ}$ Mariano Feio, não só um colaborador precioso, mas um próximo chefe de escola no primeiro daqueles ramos, com uma preparação científica que lhe permitirá chegar onde eu não poderia ir. Por isso, e porque sou no fundo um humanista, que veio para a Geografia através de sérios trabalhos históricos e etnográficos, desejava cada vez mais limitar-me à Geografia humana; sem abandonar ainda o resto do terreno e desejando levar a cabo investigações importantes que me absorveram o melhor das férias de sete anos, estimaria contudo, no programa que a seguir esboço, fazer do homem o centro dos meus trabalhos ${ }^{2}$.

Cheguei a uma altura da vida - 35 anos - em que, olhando para trás, já se ganha uma perspectiva do caminho andado; olhando para a frente, já se não vê apenas uma selva onde seria grato passar anos de aventura. O tempo começa a contar e, para chegar a um fim, há que escolher um trilho seguro e ter a coragem de abandonar o grato domínio do devaneio. Numa palavra: estou em idade de fixar e cumprir um programa, submetendo às suas inevitáveis limitações a minha actividade científica.

Um ponto desejo que fique inteiramente esclarecido. Pertenço ao número reduzido das pessoas que em Portugal devotaram a vida a uma carreira científica. Entre as ambições dessa gente, que são, [muitas] grandes, não figura geralmente a do dinheiro: a devoção à ciência, à pesquisa de factos novos e ao ensino, tem para eles tanta importância que não desejam, nem pela política nem pelas profissões de grande rendimento, fazer vista e aumentar proveitos. Mas uma coisa são ambições e outra necessidades: e qualquer homem de ciência tem o direito a um nível de vida, para si e para a sua família, que lhe permita, num ambiente de sóbrio conforto, libertar-se de preocupações materiais. Há pessoas, possuidoras de bens de fortuna ou que auferem chorudos ordenados, para quem é de mau gosto falar destas coisas. Também há muitos professores universitários que se desculpam, pela insuficiência dos ganhos, de não cumprirem a dupla missão de investigar e ensinar. É este um problema nacional que urge resolver. A solução é fácil: pagar-lhes [melhor] bem e ser inexorável com os que faltarem aos seus deveres.

Isto vem a propósito de dizer que desejo apenas consagrar-me à actividade científica e nada mais: por isso entendo investigar, ensinar, escrever trabalhos

2 Não só não abandonei a Geomorfologia, como tenho em acabamento uma extensa memória em que procuro elucidar certos pontos da evolução do relevo do Centro de Portugal (1969). 
originais e de divulgação, e colaborar sempre que me seja solicitado, em casos da vida prática que careçam de uma base ou de um tratamento científico no domínio da minha especialidade. Para prosseguir neste rumo, e porque não sou rico e tenho família já numerosa, preciso de ganhar o bastante para viver e de auxílio material para viagens e trabalhos de campo.

De trabalhar, nada nem ninguém me impedirá enquanto for professor universitário; mas é evidente que o âmbito da minha actividade científica será fixado pelas facilidades que encontrar. Num país como o nosso, onde os beneméritos apenas conhecem hospitais, asilos e associações de bombeiros voluntários, só podemos contar com o auxílio do Estado $^{3}$. Este não faz mais do que o seu dever gastando algum dinheiro com uma obra nacional.

[Desejo consagrar-me de futuro apenas a estudos de Geografia humana e regional. Tenciono acabar alguns trabalhos de Morfologia e até de Geologia que trago entre mãos, mas não encetar outros. Publicarei ainda muitos artigos, memórias, monografias e ensaios de síntese; mas toda a minha actividade visa a realização essencial das seguintes obras:]

\section{I - "LISBOA: A TERRA E A GENTE"}

Será o aproveitamento do meu ensino de "Estudos Olisiponenses". Um estudo de cidade como forma geográfica e agregado humano.

Plano:

1. Quadro geográfico.

2. Formação e crescimento.

3. As funções urbanas.

4. O porto.

5. A vida material da cidade.

6. Aspectos da estrutura social e económica da população urbana.

7. Fisionomia dos bairros.

8. Os arredores.

II - "PORTUGAL: O TERRITÓRIO, A POPULAÇÃO, A VIDA LOCAL, A ECONOMIA"

É uma Geografia de Portugal pensada em torno do homem. Dar-se-há a maior importância às diversidades regionais, parte essencial da obra, mas este estudo será precedido de uma síntese das relações geográficas da terra portuguesa e seguido de outra da nossa economia. O meu livro "Portugal, o Mediterrâneo e o Atlântico" e a "Geografia de Portugal" em colaboração com H. Lautensach (a publicar em breve) são contribuições fundamentais para este trabalho.

3 Não se sonhava sequer com a Fundação Gulbenkian... (1969). 


\section{III - “UM POVO NA TERRA” (A EXPANSÃO PORTUGUESA)}

Destina-se este livro a ser uma síntese, para me servir de feliz expressão de um autor brasileiro, do "mundo que o português criou": a terra onde a nossa gente viveu ou deixou marca. Trabalho que pressupõe muitos anos de viagens e reflexões e o conhecimento, ainda que muito rápido, das colónias portuguesas, do Brasil e dos outros núcleos de povoamento português, como a Califórnia e as Ilhas Havai. $\mathrm{O}$ assunto pode parecer vasto demais e pouco susceptível de tratar pela falta de monografias. Dos grandes povos de expansão, é o português talvez o único que um trabalho desta índole ainda possa abranger. Se conseguir escrevê-lo daqui a vinte anos, posso dar-me por satisfeito; para isso é preciso começar já.

Plano:

1. Finisterra (Portugal)

2. As ilhas perdidas (Açores, Madeira, Cabo Verde).

3. Terra de pretos (África)

4. Um sonho desfeito (Índia e Oriente)

5. Vitória nos Trópicos (Brasil)

6. Gente pobre, terras ricas (Califórnia, Ilhas Havai)

7. Humanidade, Nacionalidade.

\section{IV - MANUAL DE GEOGRAFIA HUMANA}

Depois de uma longa experiência do mundo, penso que seria útil escrever um compêndio que, sem pretender substituir-se a alguns bons livros de conjunto publicados sobre a matéria, pudesse servir de orientação de trabalho para os estudiosos de língua portuguesa: uma Geografia humana onde abundassem exemplos portugueses e brasileiros, e se indicasse a maneira de redigir trabalhos da mesma natureza.]

Para reunir o material [destas obras há] das obras que me proponho escre$v e r^{4}$ terei de alargar o horizonte de investigação onde me tenho movido com viagens frequentes e demoradas: Espanha, Marrocos, as ilhas atlântidas fronteiras (incluindo as Canárias) [podem dar-me] darão o quadro das relações geográficas do território de Portugal.

Desejava paralelamente visitar todas as colónias portuguesas. Não se trata, de modo nenhum, de escrever uma geografia completa desses territórios, mas de

4 Indicavam-se quatro livros apenas: uma Geografia de Portugal, que não desisti de escrever, um estudo comparativo da expansão portuguesa, para que continuo a juntar materiais, uma iniciação em Geografia humana, de que redigi os capítulos liminares (para quando os restantes?!) e uma monografia geográfica de Lisboa, da qual abri mão, publicando neste volume o que foi apurando para ela. Uma carreira científica está sempre sujeita a solicitações ocasionais: os propósitos, se lhe dão unidade e continuidade, é raro que possam cumprir-se integralmente (1969). 
conhecê-los, fazer ideia de conjunto deles e, aqui e além, uma sondagem monográfica mais profunda. Com os recursos da aviação, tudo isto se pode ver.

Fala-se muito em aproximação cultural com o Brasil, coisa em que, parece, ninguém está empenhado a sério. Os geógrafos franceses consideram aquele imenso país na sua esfera de influência. Porque não há-de um geógrafo português ministrar aí alguns anos de ensino, aproveitando-os para fazer algumas viagens em tão extenso território? Procurarei trabalhar neste sentido - e espero conseguir alguma coisa.

Quando se tentar que os núcleos portugueses em países estrangeiros não percam de todo o sentimento nacional, é possível se compreenda que mandando-lhes pessoas para lhes falar da terra de origem esse sentimento se revigore. Além disso, talvez ao Governo Português não fosse indiferente conhecer as condições em que essa gente vive, trabalha e se desnacionaliza. Aí está um inquérito com fim prático de que nenhum geógrafo desdenharia ocupar-se. Isto para não falar apenas da importância científica de uma investigação... um pouco cara.

O plano que fica esboçado, para os vinte ou vinte e cinco anos que a duração média da vida permite prever, parecerá talvez demasiado longo e optimista. A isso respondo que, se a concepção for mesquinha, a realização ainda o será mais: e para uma pessoa que acima de tudo põe um objectivo científico a que votou a existência, não há aqui nada que pareça inexequível. Só é preciso começar.

Para lhe dar inicio se solicita o auxílio do Ministério da Educação Nacional, por intermédio do Instituto para a Alta Cultura, e do Ministério das Colónias.

$\mathrm{O}$ que pretendo é o seguinte: 1. possibilidades materiais de viagens, para o que todos os anos apresentarei o plano pormenorizado; 2. dispensa de serviço docente durante certo tempo, alargando as férias grandes e antecipando ou não tomando parte nos exames finais - o que daria um período seguido de Junho a Dezembro, 6 meses, a melhor época de viagens no hemisfério austral; 3. dispensa de serviço docente durante todo o ano escolar, quando for necessário empreender viagens mais longas ou permanecer anos seguidos no local de trabalho; [4; manter a plenitude das prerrogativas universitárias dos professores catedráticos em exercício, tais como participar em conselhos escolares e júris de doutoramento ou concurso; 5.] conservar integralmente o vencimento da categoria e exercício, a que está inerente a regência duma cadeira; quando, eventualmente, estes trabalhos acarretam perda de vencimentos acessórios [(acumulação de regência da cadeira de Geografia Colonial Portuguesa; gratificação especial pela regência da cadeira de Estudos Olisiponenses,] obter, por uma bolsa global ou qualquer outra forma, a respectiva compensação ${ }^{5}$.

5 Tudo isto consegui, mas nunca de maneira sistemática. Fui dispensado do serviço docente, durante meses seguidos e em várias ocasiões para fazer pesquisas na Guiné, na Ilha do Fogo, na Índia e no Brasil, mas já não obtive as mesmas facilidades relativamente ao Sudoeste de Angola... embora, depois de elas me terem sido negadas, deixasse de ensinar em Lisboa para, como "professor visitante", passar um trimestre na Universidade de Laval de Quebec; aqui atendeu-se ao prestígio do convite. Quanto ao trabalho de campo, nos estudos subsidiados pela Junta de Investigações do Ultramar, manda a justiça que se diga que são grandes as facilidades e generosa a retribuição (1969). 
Ao esclarecido critério [de Suas Ex. ${ }^{\text {as }}$ ] dos Ministros das Colónias e da Educação submeto a apreciação deste memorial e deles espero as possibilidades de executar o programa aí contido. Trata-se de uma obra de alcance nacional e científico: quem deseja meter as mãos a ela não oculta a grande satisfação de a realizar, mas a essa satisfação sacrifica o cómodo conchego do gabinete, o convívio da família, e alguma coisa da saúde e mocidade; só lamenta não poder sacrificar também bens materiais - mas, porque os não possui, é que deseja deixar inequivocamente expresso que considera a eficiência das facilidades a concedera pelo Estado a condição mais importante para a levar a bom termo.

Desde que sou professor universitário que me tenho empenhado em suscitar e animar trabalhos científicos: a esta vontade de vencer obstáculos, o primeiro dos quais é a escassez de alunos, tem correspondido o Instituto para a Alta Cultura, que me confiou há três anos a direcção do Centro de Estudos Geográficos: aí desejava poder reunir e estudar o material das minhas campanhas e escolher os meus colaboradores, entre alunos ou outras pessoas que comigo têm trabalhado. Independentemente do carácter pessoal do programa que apresento, ele constitui magnífico campo para geógrafos e naturalistas, os quais me seria grato orientar e dirigir. Assim corresponderia à situação em que, bem ou mal, me vejo de facto investido, uma espécie de consultor e orientador de quem trabalha sobre estes temas portugueses.

A forma como poderei corresponder às grandes responsabilidades que voluntariamente desejo assumir, pode avaliar-se através de meio cento de trabalhos que publiquei, do nível em que tenho procurado colocar o meu ensino, e de alguns estudos que suscitei e que brevemente virão a público: se as minhas faculdades não diminuírem, como vivo para o trabalho científico com a maior devoção e entusiasmo, creio não trair a confiança que depositaram em mim as pessoas de quem, em última análise, depende a realização dos meus planos e aspirações ${ }^{6}$.

\section{Lisboa, [31 de] Março de 1946, Orlando Ribeiro}

\footnotetext{
${ }^{6}$ Escrito ainda com optimismo e esperança; comparar com a amargura do relatório seguinte, elaborado depois de nove anos de desilusões (1969). [O relatório aqui mencionado ainda não foi encontrado].
} 